\title{
Study of the number of occlusal contacts in maximum intercuspation before orthodontic treatment in subjects with Angle Class I and Class II Division 1 malocclusion
}

\author{
Gustavo Adolfo Watanabe-Kanno*, Jorge Abrão**
}

\begin{abstract}
Objective: Define and compare numbers and types of occlusal contacts in maximum intercuspation. Methods: The study consisted of clinical and photographic analysis of occlusal contacts in maximum intercuspation. Twenty-six Caucasian Brazilian subjects were selected before orthodontic treatment, 20 males and 6 females, with ages ranging between 12 and 18 years. The subjects were diagnosed and grouped as follows: 13 with Angle Class I malocclusion and 13 with Angle Class II Division 1 malocclusion. After analysis, the occlusal contacts were classified according to the established criteria as: tripodism, bipodism, monopodism (respectively, three, two or one contact point with the slope of the fossa); cuspid to a marginal ridge; cuspid to two marginal ridges; cuspid tip to opposite inclined plane; surface to surface; and edge to edge. Results: The mean number of occlusal contacts per subject in Class I malocclusion was 43.38 and for Class II Division 1 malocclusion it was 44.38, this difference was not statistically significant ( $p>0.05$ ). Conclusions: There is a variety of factors that influence the number of occlusal contacts between a Class I and a Class II, Division 1 malocclusion. There is no standardization of occlusal contact type according to the studied malocclusions. A proper selection of occlusal contact types such as cuspid to fossa or cuspid to marginal ridge and its location in the teeth should be individually defined according to the demands of each case. The existence of an adequate occlusal contact leads to a correct distribution of forces, promoting periodontal health.
\end{abstract}

Keywords: Dental occlusion. Malocclusion. Orthodontics.

How to cite this article: Watanabe-Kanno GA, Abrão J. Study of the number of occlusal contacts in maximum intercuspation before orthodontic treatment in subjects with Angle Class I and Class II Division 1 malocclusion. Dental Press J Orthod. 2012 Jan-Feb;17(1):138-47.
"The authors report no commercial, proprietary, or financial interest in the products or companies described in this article.

* MSc student in Orthodontics, School of Dentistry, University of São Paulo.

** Associate Professor of the Department of Orthodontics, School of Dentistry, University of São Paulo. 


\section{INTRODUCTION}

For a long time the basis for evaluation of success for an orthodontic treatment has been the establishment of a normal mesiodistal relation of posterior teeth, ideal overbite and overjet evaluated in a static manner. Along time, the orthodontics has assumed that only such factors are not sufficient to achieve a satisfactory functional balance. Therefore, there is a trend among orthodontists to emphasize the importance in occlusal functional analysis before orthodontic treatment. The success of orthodontic treatment is based on an optimal balance between dental and skeletal components, and requires careful evaluation of occlusal contacts to have an efficient masticatory function. ${ }^{3}$

Maximum intercuspation (MI) is the most reproducible reference position. The teeth occlude in a position where there is maximum activity of the muscles. ${ }^{21}$ The MI position is morphologically determined by the shape and position of the teeth, periodontal proprioreceptors, muscle memory and occlusal contacts. The nerve impulses enable the mandible to open and close, quickly and repeatedly in the same position. Most of the mandibular movements are functional (chewing) or parafunctional (bruxism), and occur in $\mathrm{MI}^{19}$, hence the importance of studying the occlusal contacts in that mandibular position. Also, it is important to locate the occlusal contacts in MI for maintaining the alignment of the teeth and the occlusal stability. ${ }^{10}$

On completion of orthodontic treatment, Andrews six keys of occlusion is one of the main purposes or a Class I malocclusion. Many times orthodontic treatments finish in Class II molar relationship, especially in Class II cases where molar distalizations are not part of the treatment plan. The clinician should be able to recognize and interpret the behavior of occlusal contacts in different malocclusions to obtain stability and function of the stomatognathic system, at the beginning and most especially during the end of orthodontic treatment in cases that present therapeutic limitations. There is a great variety of studies on occlusal contacts in individuals with normal occlusion. Knowing that to understand what is a malocclusion one should understand a normal occlusion, these studies are used as reference to establish means of comparison.

With the purpose of contributing for a better understanding of this subject, the aim of this study was to define and compare the number and types of occlusal contacts in maximum intercuspation in subjects with Angle Class I and Class II Division 1 malocclusions before orthodontic treatment.

\section{MATERIAL AND METHODS}

The study sample consisted of 26 untreated subjects, 20 males and 6 females, Caucasians, with ages between 12 and 18 years, at beginning of orthodontic treatment. The patients were diagnosed and grouped into 13 with Angle Class I malocclusion and 13 with Angle Class II Division 1 malocclusion, from the Orthodontic Clinic of the Dental School of São Paulo University, following these criteria: Complete permanent dentition with erupted second molars, no caries lesions, no interproximal wear, no extractions nor previous orthodontic treatment, healthy periodontal status and absence of temporomandibular joint dysfunction symptoms. This research project was approved by the Ethics Committee on Research of the University of São Paulo, report number 74/07.

Occlusal contact points were determined clinically on patients with the aid of articulated dental casts. The patient was put in a vertical position, with the back and head on a reclined dental chair, approximately 45 degrees to the floor. The patient was asked to open and close his mouth until MI was reached. After prophylaxis and drying of all teeth, the patient was asked to open and close his mouth 
in $\mathrm{MI}$ and the occlusal contacts were assessed using $12 \mu \mathrm{m}$ articulating film (Accu film II, Parkell ${ }^{\mathrm{TM}}$, Farmingdale, New York, USA). In this way, when in occlusion, the contacts were marked in black on the upper teeth and the lower teeth were marked in red. Using mouth retractors and an intraoral mirror, both arches were photographed (Fig 1).

Then polyvinyl siloxane-based occlusal registrations ( $\operatorname{Re}^{\prime} \operatorname{Cord}^{\circledR}$, Bosworth, Illinois, USA) of the posterior occlusion were obtained bi- laterally with the subjects in maximum intercuspation. Previously the subject was asked to swallow and then to close into maximum intercuspation. The bite registration material was applied to the occlusal surfaces of all lower canines, premolars, and molars both sides with a silicone gun. The subject was required to apply moderate pressure (Fig 2), comparable with the one employed for natural swallowing and chewing, to ensure that teeth were in contact, for 30 seconds. The reproducibility of this

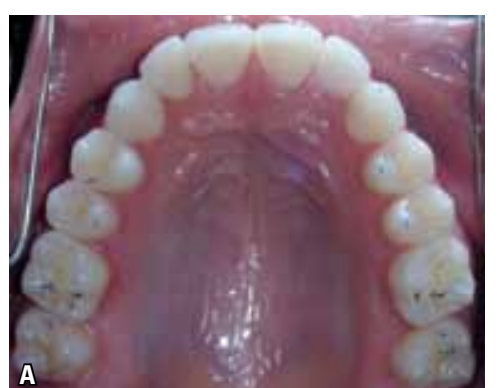

FIGURE 1 - Intraoral photograph of MI contacts in the upper $\operatorname{arch}(\mathbf{A})$ and in the lower $\operatorname{arch}(\mathbf{B})$.

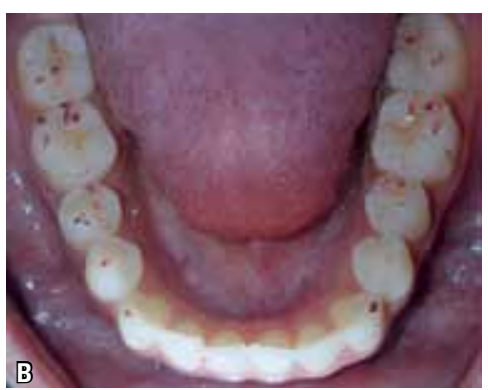

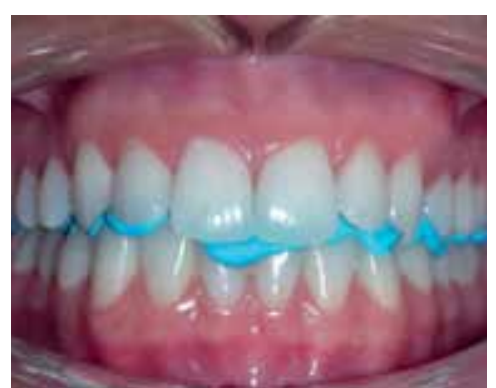

FIGURE 2 - Occlusal registration in MI.

TABLE 1 - Types of occlusal contacts definitions.

\begin{tabular}{|c|c|}
\hline Types of Occlusal Contacts & Definition \\
\hline Tripodism & Centric retention cusp contacts the perimeter of the slopes of the opponent fossa in three points.,22 \\
\hline Bipodism & Centric retention cusp contacts the perimeter of the slopes of the opponent fossa in two points. ${ }^{4}$ \\
\hline Monopodism & Centric retention cusp contacts the fossa in one individual point. ${ }^{23}$ \\
\hline Cusp to marginal ridge & Contact between the cusp tip and the opposite marginal ridge. ${ }^{23}$ \\
\hline Cusp to two marginal ridges & Two contacts between the cusp tip and two opposite marginal ridges. ${ }^{22}$ \\
\hline Cusp to opposite inclined plane & $\begin{array}{l}\text { Individual contact of the cusp tip and the internal slope, external slope, mesial or distal } \\
\text { slope on the opposite side. }\end{array}$ \\
\hline Surface to surface & Individual contact between two opposing slopes. ${ }^{8}$ \\
\hline Edge to edge & Individual contact between cusp tip and cusp tip on the opposite side. ${ }^{8}$ \\
\hline
\end{tabular}



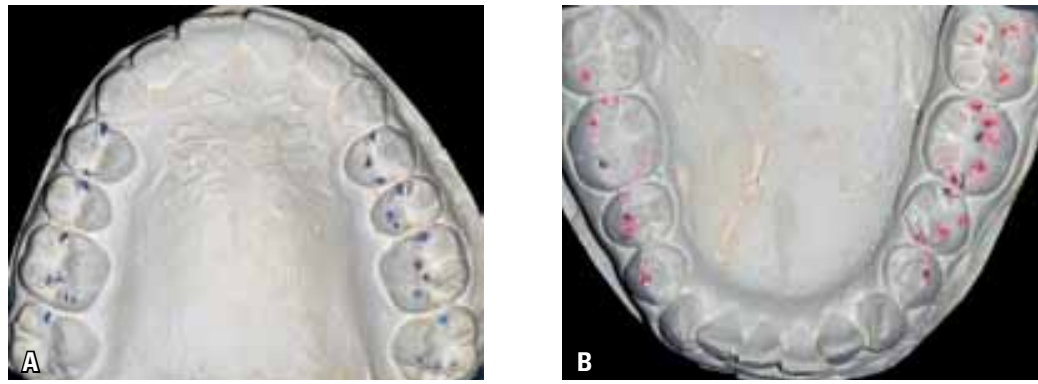

FIGURE 3 - Occlusal contacts in articulated study casts: A) upper and B) lower.

procedure was checked with the polyvinyl siloxane bite record in maximum intercuspation position; the perforations of the record had to coincide with the occlusal contacts clinically marked with the articulating film. In addition, dental casts were mounted on semi-adjustable articulator (Bio-Art ${ }^{\circledR} 4000$ ) in MI. This procedure was performed to facilitate the determination of the occlusal contacts types (Table 1), using Arti-Fol $8 \mu \mathrm{m}$ articulating film (Bausch, Köln, Germany) (Fig 3).

\section{STATISTICAL ANALYSIS}

Data was analyzed using the statistical software SPSS version 16.0 for Windows (SPSS Inc., Chicago, USA) and graphs were constructed using Microsoft Excel 2007. Sample normality and homogeneity of variances were determined using Kolmogorov-Smirnov $Z$ test. Student $t$-test was used to determine any statistically significant differences in the observed number and location of occlusal contacts between the different types of malocclusions (level of significance at 5\%).

\section{RESULTS}

The Kolmogorov-Smirnov test demonstrated that values had a normal distribution ( $p>0.05$ ), therefore comparisons between malocclusion values were performed with parametric tests based on the sample distribution.
Number of occlusal contacts in maximum intercuspation (MI)

The comparison between the mean occlusal contacts in MI on the upper and lower arches, according to the malocclusion is described in Table 2, and demonstrated that:

» The mean number of total occlusal contacts in Angle Class I malocclusion was 43.38 contacts and in Class II Division 1 it was 44.38. According to the paired t-test there was no statistical difference $(p=0.79)$.

" The mean of occlusal contacts on the right side was 10.20 (range 7 to 22) and on the left side it was 11.5 (range 6 to 17) for Class I malocclusions. For the Angle Class II Division 1 malocclusion the mean of occlusal contacts was 11.8 (range 8 to 15 ) on the right side and 10.39 (range 5 to 15 ) on the left side. No significant difference was observed between the two types of malocclusion.

» The means of occlusal contacts on lower premolars in Class I and Class II Division 1 malocclusions were 2.62 and 3.92, respectively. This difference was statistically significant $(\mathrm{p}=0.03)$.

\section{Distribution of occlusal contacts}

Class I malocclusion had a total of 237 contacts of the evaluated types and Class II 
Division 1 a total of 246 contacts (Table 3). The highest concentration of the contacts was for the upper and lower first molars in both the Class I malocclusion and Class II Division 1, which had, respectively, an average of $39.12 \%$ and $38.87 \%$ of all contacts recorded (Fig 4). The second molars had an average of $25.03 \%$ and $22.9 \%$ of total contacts accounted, respectively. The first lower premolar presented the smallest number of contacts both in Angle Class I and Class II Division 1, reaching
$10.87 \%$ and $16.60 \%$, respectively. Analyzing the distribution of occlusal contacts in the cuspids, fossa and marginal ridges in Figure 5 , we can conclude that from the totality of the contacts made by the centric contention cuspid, $45.07 \%$ corresponded to the cuspids of upper teeth and $54.93 \%$ to the cuspids of lower teeth in the Class I malocclusion; and $48.34 \%$ corresponded to the cuspids of upper teeth and $51.66 \%$ to the cuspids of lower teeth in Angle Class II Division 1 malocclusion.

TABLE 2 - Comparison between means of occlusal contacts in MI on the upper and lower arches.

\begin{tabular}{|c|c|c|c|c|c|c|c|c|c|}
\hline \multirow[t]{2}{*}{ Variables } & \multirow{2}{*}{ Mean } & \multicolumn{3}{|c|}{ Class I malocclusion } & \multicolumn{4}{|c|}{ Class II Division 1 malocclusion } & \multirow{2}{*}{$\begin{array}{l}\text { Paired t test } \\
\text { p-value }\end{array}$} \\
\hline & & SU & Minimum & Maximum & Mean & SD & Minimum & Maximum & \\
\hline Upper first premolars occlusal contacts & 3.38 & 2.29 & 0.00 & 9.00 & 4.38 & 0.87 & 3.00 & 6.00 & 0.16 \\
\hline Upper second premolars occlusal contacts & 4.85 & 1.91 & 2.00 & 8.00 & 4.54 & 0.88 & 3.00 & 6.00 & 0.60 \\
\hline Upper first molars occlusal contacts & 8.08 & 2.56 & 4.00 & 14.00 & 8.00 & 1.68 & 6.00 & 11.00 & 0.93 \\
\hline Upper second molars occlusal contacts & 5.31 & 2.63 & 2.00 & 13.00 & 5.31 & 3.04 & 2.00 & 11.00 & 0.99 \\
\hline Lower first premolars occlusal contacts & 2.62 & 1.80 & 0.00 & 6.00 & 3.92 & 0.76 & 3.00 & 5.00 & $0.03^{*}$ \\
\hline Lower second premolars occlusal contacts & 5.00 & 1.58 & 3.00 & 9.00 & 4.77 & 1.36 & 2.00 & 7.00 & 0.69 \\
\hline Lower first molars occlusal contacts & 8.15 & 2.34 & 5.00 & 14.00 & 8.23 & 1.69 & 6.00 & 12.00 & 0.92 \\
\hline Lower second molars occlusal contacts & 6.00 & 2.74 & 2.00 & 13.00 & 5.23 & 2.68 & 2.00 & 10.00 & 0.48 \\
\hline Upper right side occlusal contacts & 10.08 & 3.38 & 7.00 & 20.00 & 12.00 & 1.83 & 9.00 & 15.00 & 0.08 \\
\hline Upper left side occlusal contacts & 11.54 & 3.26 & 6.00 & 17.00 & 10.23 & 2.42 & 5.00 & 14.00 & 0.26 \\
\hline Lower right side occlusal contacts & 11.46 & 2.79 & 7.00 & 16.00 & 10.54 & 3.07 & 5.00 & 15.00 & 0.43 \\
\hline Lower left side occlusal contacts & 10.31 & 3.97 & 7.00 & 22.00 & 11.62 & 1.56 & 8.00 & 14.00 & 0.28 \\
\hline Total occlusal contacts & 43.38 & 11.63 & 27.00 & 75.00 & 44.38 & 6.02 & 32.00 & 53.00 & 0.79 \\
\hline
\end{tabular}

* Level of significance $p<0.05$.

TABLE 3 - General distribution of the types of occlusal contacts in absolute numbers.

\begin{tabular}{|c|c|c|c|c|c|c|c|c|c|}
\hline \multicolumn{10}{|c|}{ Class I malocclusion } \\
\hline Types of occlusal contacts & A & B & C & D & $\mathbf{E}$ & $\mathbf{F}$ & G & H & Total number \\
\hline Number of occlusal contacts according to type & 6 & 32 & 36 & 49 & 33 & 27 & 51 & 3 & 237 \\
\hline Total number of occlusal contacts & 18 & 64 & 36 & 49 & 66 & 27 & 51 & 3 & 314 \\
\hline \multicolumn{10}{|c|}{ Class II Division 1 malocclusion } \\
\hline Types of occlusal contacts & A & B & C & D & $\mathbf{E}$ & $\mathbf{F}$ & G & H & Total number \\
\hline Number of occlusal contacts according to type & 9 & 27 & 46 & 34 & 31 & 24 & 74 & 1 & 246 \\
\hline Total number of occlusal contacts & 27 & 54 & 46 & 34 & 62 & 24 & 74 & 1 & 322 \\
\hline
\end{tabular}

$A=$ Tripodism, $B=$ Bipodism, $C=$ Monopodism, $D=$ Cusp to one marginal ridge, $E=$ cusp to two marginal ridges, $F=$ cusp tip to opposite slope, $G=$ surface to surface, $\mathrm{H}=$ edge to edge. 

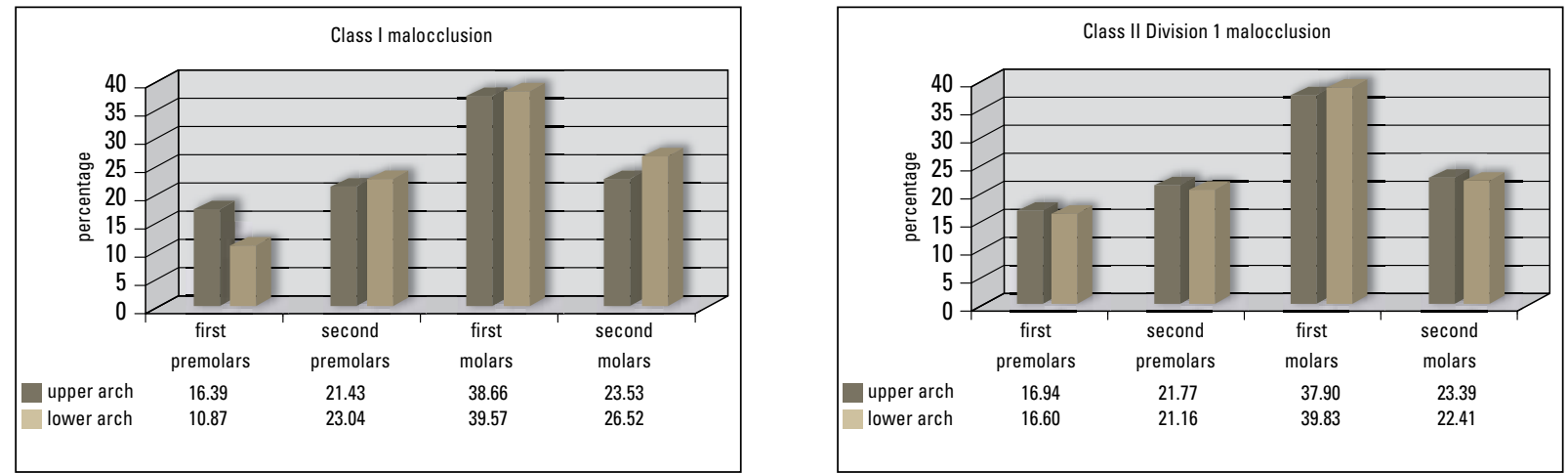

FIGURE 4 - Distribution of occlusal contacts on the upper and lower arches, in percentage, according to the malocclusion.
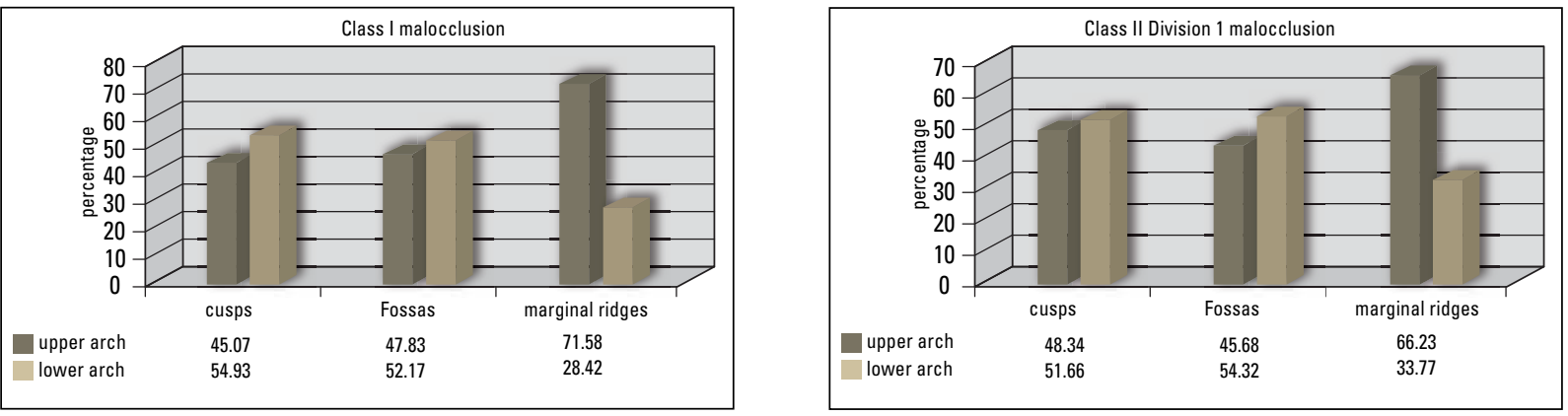

FIGURE 5 - Distribution of occlusal contacts on the cusps, fossas and marginal ridges, in percentage, according to the malocclusion.
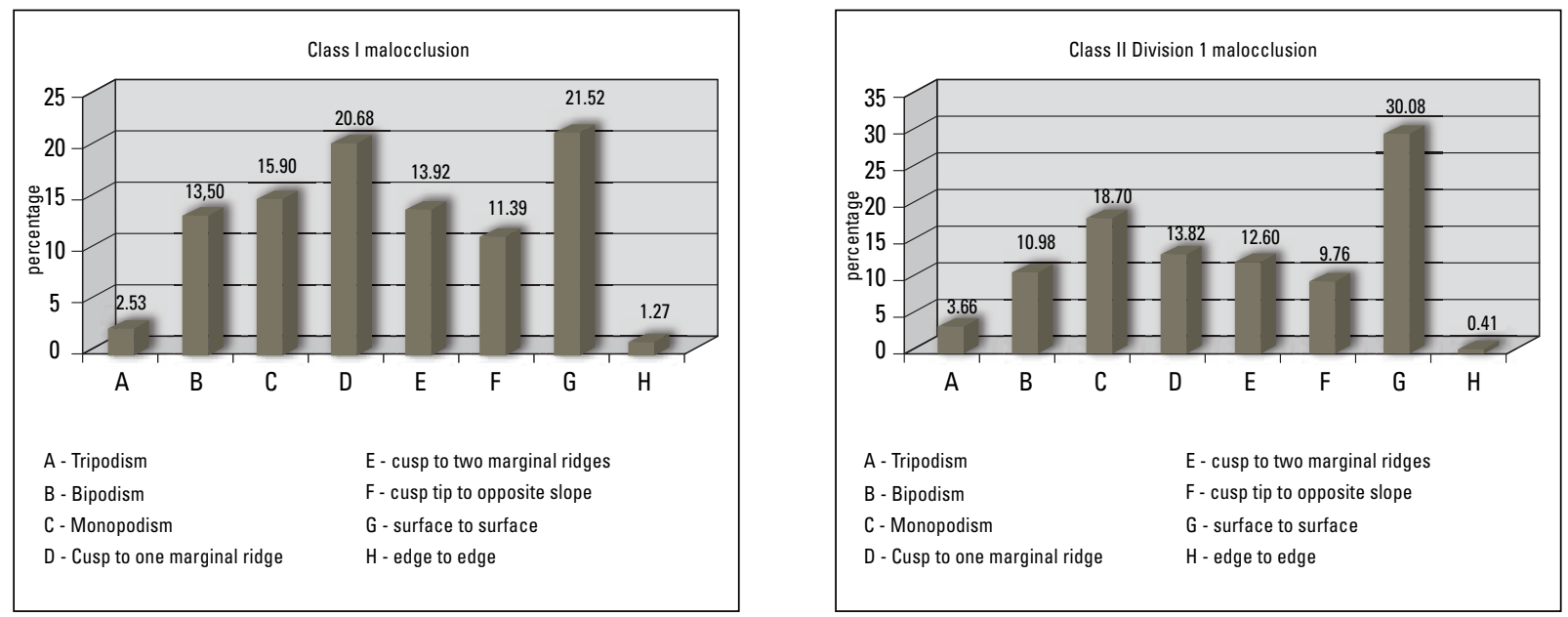

FIGURE 6 - Distribution of types of occlusal contacts, in percentage, according to the malocclusion.

On the other hand, the marginal ridges of the upper teeth had the most contacts in both Class I and Class II Division 1 malocclusions, totaling $71.58 \%$ and $66.23 \%$, respectively.

\section{Types of occlusal contacts}

In Class I malocclusion (Fig 6), from a total of 237 registered contacts, the higher frequency of occlusal contact types corresponded 
to the surface to surface and a cuspid to marginal ridge in $21.52 \%$ and $20.68 \%$, respectively. Thus, the tripodism and edge to edge occlusal contacts registered the smallest percentage of total, with $2.53 \%$ and $1.27 \%$ respectively. On the other hand, in Angle Class II Division 1, from a total of 246 occlusal contacts, the most frequent contact types corresponded to the surface to surface (30.08\%) and monopodism $(18.70 \%)$. The lower frequency was shown by tripodism $(3.66 \%)$ and edge to edge $(0.41 \%)$.

\section{DISCUSSION}

Comparing the occlusal contacts in maximum intercuspation, between both malocclusions, there were no significant differences. There were no significant differences in most of the variables with the exception of the occlusal contacts on first mandibular premolars. Especially the Class II Division 1 malocclusion showed a higher average of contacts in that tooth, because of the skeletal and dental distal relationship typical characteristic of this malocclusion when compared to Class I malocclusion.

These results are also related to the shape and function of the lower first premolar during mastication. The lower first premolar is the only posterior tooth with a lingual inclination in relation to the occlusal plane, it also has a larger buccal cusp in comparison to the lingual cusp. This shape variation is due to the primary function of the buccal cusp during mastication. This cusp is responsible for perforating food, establishing a primary contact, then the lingual cusp performs the second function which is to grind the food without contacting its antagonist tooth in MI..$^{5,18}$

In our study, the shape of the lower premolar lingual cusp in Class I malocclusions was mostly smaller than in the Class II Division 1 malocclusion. This finding explains why the Class I malocclusion presented lower number of contacts in this tooth.
The total average of occlusal contacts in Class I malocclusion was 43.38 and in Class II Division 1 malocclusion was 44.38. Considering the mean number of contacts per arch, it was observed that patients with Class I malocclusion had 21.69 contacts and in Class II Division $1,22.19$. This agrees with Gondim et $\mathrm{al}^{14}$ that registered an average of 23.20 contacts per arch and Oliveira ${ }^{22}$ with 20.5 contacts, 22 maxillary contacts and 19 mandible contacts in patients with natural normal occlusions. Athanasiou et $\mathrm{al}^{6}$ established an average of 23.8 contacts per arch in subjects with normal occlusion using the technique of photo-occlusion. Thus, Ricketts ${ }^{25}$ also recorded an average of 24 occlusal contacts for patients with normal occlusions. However, as for the number of dental occlusal contacts, Velmovitsky ${ }^{29}$ found in his study an average of 24.89 contacts in all patients-in disagreement with Hellman, ${ }^{16}$ which found 138 possible contacts in a normal occlusion, ranging from 90 to 103 for 28 teeth, and Anderson and Myers $^{2}$ with 565 occlusal contacts evaluated on 32 subjects with an average of 17.7 contacts.

Considering that this research was performed in patients with Class I and Class II Division 1 malocclusions, it can be inferred therefore that small changes in individual and dental positions seem not to produce severe changes in the quantitative behavior of dental occlusal contacts in subjects with complete dentition, but does produce changes regarding their distribution and localization. This fact also explains that no significant differences were found between the mean contact points between the studied malocclusions.

In Class II Division 1 there are no contact between anterior teeth (canine to canine), so only posterior contacts were considered, 246 contacts of the 13 subjects with Class II Division 1 showed an average of 22.19 occlusal contacts, similar to the findings of McNamara and Henry ${ }^{20}$ with an average of 19.7, Riise and Ericsson ${ }^{26}$ with 
an average of 18.15, and Taicher and Ehrlich ${ }^{10}$ with an average of 39.5 , Garrido et $\mathrm{al}^{12}$ with an average of 19.43, and Gondim et $\mathrm{a}^{14}$ with an average of 18.9. This average was relatively higher in comparison to other studies: Aoki et $\mathrm{al}^{4}$ with an average of 7.14, Gazit and Lieberman ${ }^{13}$ with an average of 9.30 (normal occlusion) and 7.60 (malocclusion), Korioth ${ }^{17}$ with an average of 14.0, McDevitt and Warreth ${ }^{19}$ with an average of 11.5 , and Ferrario et $\mathrm{al}^{11}$ with an average of 13.0. Considering that these studies were developed in conditions of normal occlusion and using different methodologies as indirect determination of the occlusal contacts using interocclusal records, T-Scan or using different types of articulation papers, even so this research has reported results without significant differences when compared with other studies mentioned above.

In this study the occlusal contact types such as monopodism, bipodism and tripodism, in their majority concentrates on the first molars in descending order, both in Angle Class I and Class II Division 1 malocclusions. However, in Class I malocclusion, the monopodism occlusal contact type was located on distobuccal cuspid and the central fossa of the first mandibular molar, and the central fossa and the palatal mesial cuspid of the first maxillary molar. In prosthodontics there is no established occlusal pattern and the occlusal types of contacts could be modified individually. ${ }^{7}$

Thus, the relationship cuspid-fossa is the most stable because it tends to direct the forces on the long axis of the teeth and with almost no lateral pressures and the relationship cuspid to one marginal ridge tends to separate the contact points and create an unstable occlusion. ${ }^{23}$ The first molars have greater physiological limit, to withstand an amount of load without damaging the periodontal ligament. ${ }^{15}$ When occlusal forces are applied to the long axis of the tooth it absorbs certain loads without raising the proprioceptive sensors.
The contact type cuspid to two marginal ridges was located mainly in the second premolar, with similar distribution between upper and lower arches. This type of occlusal relationship can also be considered according to the literature as physiological, because it tends to distribute the occlusal load close to the long axis of the teeth, with the disadvantage of promoting in some cases interproximal separation. ${ }^{1}$

According to the types of occlusal contacts in both malocclusions, Class I and Class II Division 1 , the type of occlusal contact surface to surface had the greater frequency. This type of occlusal contact does not promote stabilization of the mandible, creating tangential or horizontal forces on the supporting structures of the teeth, maintaining the muscles next to a very high level of activity. The anterior teeth that had occlusal contact occluded on an inclined plane, considered clinically normal and stable. In anterior and posterior teeth with this type of occlusal contact there should be a balance in physiological forces of the tongue, lips, cheeks and occlusion, to maintain its relative position. ${ }^{2}$ Posterior teeth are dependent on this same balance of forces for their physiological stability position. Through continuous eruption or modification in buccal forces, the posterior teeth can slide down on inclined planes to a new position, thus establishing its final occlusal stop. The vertical forces are more easily tolerated because they are directed to the apical region where there is a bone density, for example, cuspid-fossa contacts. ${ }^{27}$ Lateral forces are more destructive because they are directed against a buccal and lingual alveolar wall, which are fragile and very thin.

In this research, there was a high incidence of these types of occlusal contacts mainly in Angle Class II Division 1 malocclusion, basically due to altered anteroposterior and transverse relationship of dental arches, a skeletal characteristic of this malocclusion. 


\section{CONCLUSIONS}

1. The average number of occlusal contacts per patient in Class I malocclusion was 43.38 and in Class II Division 1 malocclusion was 44.38, and this difference was not statistically significant. There is a variety of factors that influence the number of occlusal contacts, such as small changes in individual tooth positions (rotations, infraocclusion, extrusion, linguoversions, buccal, mesial and distal displacements) and the anteroposterior and transverse relationship between jaws and the occlusal morphology of teeth related to the mastication.

2. There is no standardization of the types of occlusal contacts in relation to the studied malocclusions, even when compared with studies in normal occlusal conditions, which shows the same variability. A proper selection of a cuspid-fossa or cuspid-marginal ridge contact and its location in teeth can be individually changed according to the requirements of each case. 


\section{REFERENCES}

1. Abrão J. Análise oclusal em pacientes ao término do tratamento ortodôntico empregando-se a técnica de arco de canto. [tese]. São Paulo (SP): Universidade de São Paulo; 1991.

2. Anderson JR, Myers GE. Nature of contacts in centric occlusion in 32 adults. J Dent Res. 1971;50(1):7-13.

3. Brandão RCB, Brandão LBC. Ajuste oclusal na Ortodontia: por que, quando e como? Rev Dental Press Ortod Ortop Facial. 2008;13(3):124-56.

4. Aoki H, Shimizu T, Shimizu Y, Yoshino R. Clinical evaluation of the occlusion of natural dentition by means of a semi-adjustable articulator. Bull Tokyo Dent Coll. 1970;11(4):211-21.

5. Arnold N, Frumker SC. Occlusal treatment: preventive and corrective occlusal adjustment. Philadelphia: Lea \& Febiger;1976.

6. Athanasiou AE, Melsen B, Kimmel P. Occlusal tooth contacts in natural normal adult dentition in centric occlusion studied by photocclusion technique. Scand J Dent Res. 1989;97(5):439-45.

7. Beyron H. Occlusion: point of significance in planning restorative procedures. J Prosthet Dent. 1973;30(4):641-52.

8. Ciancaglini R, Gherlone EF, Redaelli S, Radaelli G. The distribution of occlusal contacts in the intercuspal position and temporomandibular disorder. J Oral Rehabil. 2002;29(11):1082-90.

9. Dawson PE. Avaliação, diagnóstico e tratamento dos problemas oclusais. São Paulo: Artes Médicas; 1993.

10. Ehrlich J, Taicher S. Intercuspal contacts of the natural dentition in centric occlusion. J Prosthet Dent. 1981;45(4):419-21.

11. Ferrario VF, Serrao G, Dellavia C, Caruso E, Sforza C. Relationship between the number of occlusal contacts and masticatory muscle activity in healthy young adults. Cranio. 2002;20(2):91-8.

12. Garrido García VC, García Cartagena A, González Sequeros $O$. Evaluation of occlusal contacts in maximum intercuspation using the T-Scan system. J Oral Rehabil. 1997;24(12):899-903.

13. Gazit E, Lieberman MA. The intercuspal surface contact area registration: an additional tool for evaluation of normal occlusion. Angle Orthod.1973;43(1):96-106.

14. Gondim NFR, Paiva HJ, Paiva AMFV, Duarte ARC. Comportamento clínico dos contatos oclusais nas posições de máxima intercuspidação (PMI) e máxima intercuspidação habitual (MIH). Rev ABO Nac. 2003; 11(1):53-59.
15. Guichet NF. Biologic laws governing functions of muscles that move the mandible. Part II. Condylar position. J Prosthet Dent. 1977;38(1):35-41.

16. Hellman M. Variations in occlusion. Dent Cosmos. 1921; 63(6):608-19.

17. Korioth TW. Number and location of occlusal contacts in intercuspal position. J Prosthet Dent. 1990;64(2):206-10.

18. Kraus B, Jordan RE, Abrams L. Anatomia dental y oclusión. México: Interamericana; 1972.

19. McDevitt WE, Warreth AA. Occlusal contacts in maximum intercuspation in normal dentitions. J Oral Rehabil. 1997;24(10):725-34

20. McNamara DC, Henry PJ. Terminal hinge contact in dentitions. J Prosthet Dent. 1974;32(4):405-11.

21. Moller E. The chewing apparatus. An electromyographic study of the action of the muscles of mastication and its correlation to facial morphology. Acta Physiol Scand Suppl. 1966;280:1-229.

22. Oliveira MLC. Estudo clínico e fotográfico do número e localização de contatos oclusais na posição de máxima intercuspidação (P.M.I) em oclusões normais [dissertação]. Recife (PE). Universidade de Pernambuco; 1996.

23. Pokorny DK. Current procedures in fixed prosthodontics. Dent Clin North Am. 1971;15(3):685-710.

24. Ramfjord S, Ash MM. Oclusão. Rio de Janeiro: Interamericana,1984. p. 329-337.

25. Ricketts RM. Occlusion: the medium of dentistry. J Prosthet Dent. 1969;21(1):39-60.

26. Riise C, Ericsson SG. A clinical study of the distribution of occlusal tooth contacts in the intercuspal position at light and hard pressure in adults. J Oral Rehabil. $1983 ; 10(6): 473-80$

27. Ross IF. Occlusal contacts of the natural teeth. J Prosthet Dent. 1974;32(6):660-7.

28. Simões WA. Ortopedia funcional dos maxilares através da reabilitação neuro-oclusal. São Paulo: Artes Médicas; 2003.

29. Velmovitsky L. Avaliação clínica comparativa de contatos interoclusais entre o método computadorizado e o método associado de fitas plásticas e shimstock [dissertação]. São Paulo (SP): Universidade de São Paulo; 1992. 